\title{
Investor demand in syndicated bond issuances: stylised facts
}

This paper analyses investor demand dynamics in primary bond markets, looking at different market segments, investor types, pricing impact, and demand overshooting.

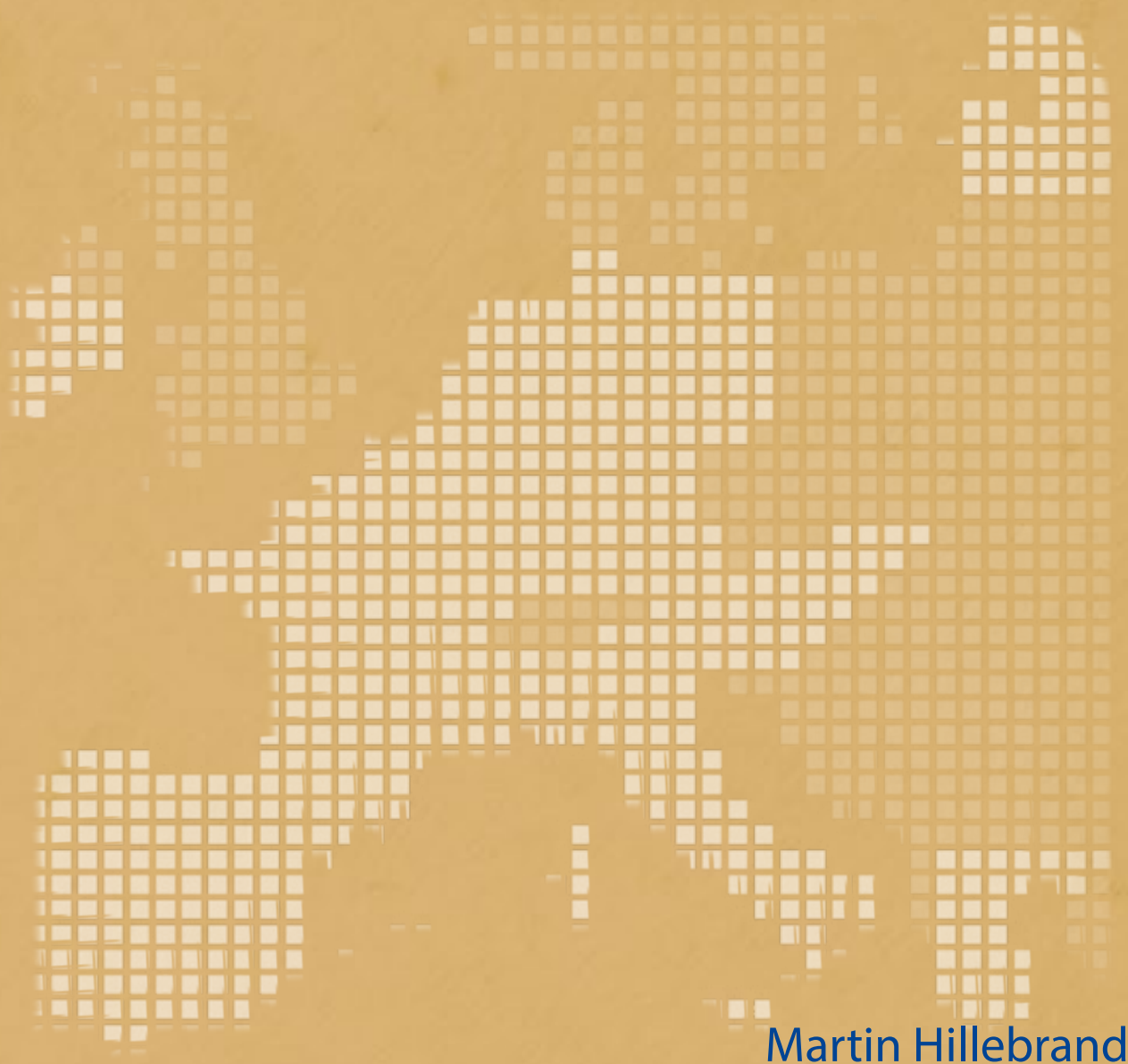

European Stability Mechanism

Marko Mravlak

European Stability Mechanism

Peter Schwendner

Zurich University of Applied Sciences

\section{Disclaimer}

This working paper should not be reported as representing the views of the ESM. The views expressed in this Working Paper are those of the authors and do not necessarily represent those of the ESM or ESM policy. 


\title{
Investor demand in syndicated bond issuances: stylised facts
}

\author{
Martin Hillebrand ${ }^{1}$ European Stability Mechanism \\ Marko Mravlak² European Stability Mechanism \\ Peter Schwendner ${ }^{3}$ Zurich University of Applied Sciences
}

\begin{abstract}
This study analyses investor demand in syndicated EFSF and ESM bond issuances from 2014 to 2020 on an unprecedented granularity level of individual orders. In particular, we investigate three main aspects of order book dynamics: first, we determine the main factors segmenting investor demand. Second, we analyse price dynamics in the transactions and its relation to investor demand. Third, we examine whether there are any indications of order book inflation that might explain the increased volatility in order book volume. We identify issuance tranche and tenor as the main determinants of investor demand, which are to a large extent anticipated by the envisaged notional amount of the issuance. Further, we note that the pricing of ESM bond issuances is carried out in an economical manner, i.e. the new issue premium tends to be lower in a market context with large demand. Lastly, we look at the drivers of large order books and find a mixture of above average number and volume of orders. This confirms that there are no indications of order book inflation tendencies in the analysed time period.
\end{abstract}

Keywords: Investor demand, bond issuance, bond syndication, bond primary market, investor behaviour, order books, order book inflation, new issue premium

JEL codes: G12, G15, G23, G40

\footnotetext{
1 m.hillebrand@esm.europa.eu

2 m.mravlak@esm.europa.eu

${ }^{3}$ scwp@zhaw.ch
}

\section{Disclaimer}

This Working Paper should not be reported as representing the views of the ESM. The views expressed in this Working Paper are those of the authors and do not necessarily represent those of the ESM or ESM policy. No responsibility or liability is accepted by the ESM in relation to the accuracy or completeness of the information, including any data sets, presented in this Working Paper. 


\title{
Investor demand in syndicated bond issuances: stylised facts
}

\author{
Martin Hillebrand, Marko Mravlak, Peter Schwendner ${ }^{1}$
}

\begin{abstract}
This study analyses investor demand in syndicated EFSF and ESM bond issuances from 2014 to 2020 on an unprecedented granularity level of individual orders. In particular, we investigate three main aspects of order book dynamics: first, we determine the main factors segmenting investor demand. Second, we analyse price dynamics in the transactions and its relation to investor demand. Third, we examine whether there are any indications of order book inflation that might explain the increased volatility in order book volume. We identify issuance tranche and tenor as the main determinants of investor demand, which are to a large extent anticipated by the envisaged notional amount of the issuance. Further, we note that the pricing of ESM bond issuances is carried out in an economical manner, i.e. the new issue premium tends to be lower in a market context with large demand. Lastly, we look at the drivers of large order books and find a mixture of above average number and volume of orders. This confirms that there are no indications of order book inflation tendencies in the analysed time period.
\end{abstract}

Keywords: investor demand, bond issuance, bond syndication, bond primary market, investor behaviour, order books, order book inflation, new issue premium

JEL classifications: $\mathrm{G} 12, \mathrm{G} 15, \mathrm{G} 23, \mathrm{G} 40$

\footnotetext{
${ }^{1}$ The views expressed in this paper are those of the authors and do not necessarily reflect those of the European Stability Mechanism (ESM). The authors would like to thank Niels Hansen, Lorenzo Ricci, Silke Weiss, Juergen Klaus and the participants of an ESM Research Seminar for helpful comments. E-mail: m.hillebrand@esm.europa.eu,m.mravlak@esm.europa.eu, scwp@zhaw.ch.
} 


\section{Introduction}

Solid primary market investor demand is a fundamental prerequisite of the ability of a supranational institution to cover its financing needs directly in the capital market. Understanding the investor demand dynamics is of outmost importance for the issuer to raise funds costeffectively and access the market successfully, even in turbulent market conditions. This paper looks at three crucial aspects of investor demand: first, it looks at the specific investor demand situation for different market segments in terms of tranche and tenor.

Second, it analyses how investor demand is connected to price dynamics, particularly the new issuance premium (NIP) that the issuer can offer to attract investors.

Third, it investigates drivers of extreme demand dynamics, namely large order books. These have occurred with increasing frequency over the past years among large issuers, and the question is whether they reflect real demand dynamics or rather tactical bidding behaviour.

A better understanding of these three aspects immediately supports the issuance business: it helps with the planning, delivers relevant information for the execution (pricing), and gives input for the investor allocation. Naturally, investors are also interested in understanding the demand situation, as a diversified investor base and efficient market mechanism are crucial for reliable secondary markets. This paper is able to provide new insights into investor-specific behaviour because it is based on a dataset of unique size and granularity, containing more than 10,000 orders placed in approximately 100 transactions and more than 14,000 investors which are categorised by investor type.

One key instrument for large funding needs is a standard bearer bullet ("plain vanilla") Eurobond structure which is usually issued in a syndicated format. Large and top-rated sovereigns like the US, France, and Germany usually rely on auctions, as Goldreich (2007) explained to place their bonds through a network of primary dealers who buy the bond issues from the government and sell it to other banks and investors. Agency, corporate, smaller sovereign and supranational issuers, such as the European Stability Mechanism (ESM) and the European Financial Stability Facility (EFSF) tend to use a syndicate of banks who collect orders from their client base in a joint order book (a so-called "pot"). Generally, syndications are more often used for bonds that have a smaller market, such as bonds with longer tenors or new products like green bonds.

Syndicate banks, also called (co-)lead managers or underwriters, are usually obliged to buy the unsold amounts of the bond issuance. This risk is covered by the issuance fee paid by the issuer to the syndicate banks. Therefore, they are keen to fill the order book quickly and have a certain oversubscription, such that the issuer has some freedom when allocating the bonds, considering investor diversity aspects and favouring preferred investors. These are e.g. investors that are of strategic importance, regular buyers, or investors with supportive behaviour in the secondary market. The latter particularly implies not selling the newly issued bond immediately on the secondary market as this could lead to initial weak secondary market performance. Usually, the price discovery during a syndicated transaction leads to a higher price than in the secondary market, hence showing a positive new issue premium (NIP). Buis et al. (2020) highlight the institutional setting of the European primary and secondary sovereign bond markets. They point out syndicate banks are providing liquidity in secondary markets to qualify for primary market syndicates.

Once a bond is issued, it can be re-opened (tapped). This means that the issuers offer another tranche of the same bond. Economically, there is a difference between issuing a new bond and tapping an existing bond. While in the latter case, a secondary market already exists for this bond, which is not the case for a bond's first (or "inaugural") issuance. Typically, the first issuance has a 
substantial issuance volume, also called "benchmark size" to enable the development of a sufficiently liquid secondary market. Hence, we subsequently use the term "benchmark issuance" for first issuances. It appears natural to consider the tranche when looking at the investor demand of different issuances. The use of taps (reopenings) of bonds has been analysed in detail for auctioned sovereign bonds, e.g. for Italian bonds (Scalia et al., 1997), or corporate bonds (Maul \& Schiereck, 2018).

One main characteristic of a bond transaction is the tenor, which is the time to maturity at issuance. The tenor is one of the most important determinants of investor demand. Bonds with long tenors usually offer higher coupons at higher market risk, and many investors are entirely focused on specific tenors. Also, issuers have certain tenor preferences, as it is widely discussed in the literature, such as recently in Beetsma et al (2021). Many authors suggest methods to optimise the choice of tenor in public debt management. For example, Greenwood et al (2015) and Athanasopoulou et al (2018) suggest an optimal choice of tenors considering both borrowing costs and refinancing risk. In contrast, our focus here is the investor demand aspect of the tenor.

Another relevant constituent of a bond transaction is the pricing. Here we focus on the yield difference of the issuance to a comparable yield, most of the time a corresponding secondary market yield, or a composition (e.g. linear combination) of several secondary market bond yields. Usually, yield difference (also called new issue premium, or NIP) is positive, which means that the issuer is ensuring an attractive yield for the investors to obtain a good liquidity for the newly issued bond. In an ideal bond transaction, the NIP is not too generous in market environments that indicate low investor demand. The NIP needs to be higher to incentivise investors to participate in the transaction, whereas this is not necessary in market environments where investor demand is large. In the latter case, the NIP should be relatively small. In reality there are other success factors to be considered as well, yet careful pricing can be regarded as a quality indicator for a transaction. Maitra et al. (2018) and Maul and Schiereck (2018) analyse new issue premia in the European corporate bond market, whereas the bulk of the literature like Goldberg and Ronn (2013), Ben Dor and Xu (2015), Nagler and Ottonello (202) and Jud (2020) addresses the US corporate bond market. Most studies find positive new issue premia in corporate bond markets. However, Matsui (2006) finds a negative new issue premium for Japanese corporate bond issued from 1995-2000.

A third phenomenon in investor demand dynamics that we investigate are very large order books. The background to it is as follows: investors that expect to be only partially allocated might increase their order so that the allocated volume they expect would better match their demand. When there are indications of large demand (e.g. a quick tightening of the price guidance), this might lead to very large order volumes: investors would expect large orders of other investors and therefore increase their order a second time. This means that order volumes would not necessarily show real demand; there would be an overshoot instead, by different magnitudes. Indeed, such investor behaviour has been observed in the markets: Ding et al. (2020) report significant overpricing for the Chinese corporate bond market measured by weak performance on the first trading day on the secondary market.

The following analysis is based on the secondary markets for ESM and EFSF bonds. Due to the relevance of the ESM and EFSF for financial stability in the euro area and their key role in supporting its integrity during the European sovereign debt crisis of 2010-2012 (Moessner 2018), a deeper understanding of their bond markets warrants broader interest. Furthermore, since the ESM and EFSF have jointly been among the largest supranational bond issuers in euros recently, they can be regarded as important representatives of the European SSA ${ }^{2}$ segment. In contrast to

\footnotetext{
${ }^{2}$ SSA is used as an abbreviation of "sovereigns, supranationals and agencies", but also of "supranationals, subsovereigns and agencies"
} 
the cited literature above, we analyse order books on the granular level of individual orders, which allows particularly for a distinction between investor types.

This working paper is structured as follows: in Chapter 2, we look at the main factors segmenting investor demand, the tenor and the issuance tranche of the bond. We quantify the relevance of tenor and tranche on the demand volume. Particularly, we investigate whether demand for first transactions is higher than for taps, and whether demand for longer tenors is smaller than for shorter tenors. Then, we discuss how this has been reflected in the notional issued in the observation period. These insights may help issuers plan the distribution of funding needs into different tenors and issuance tranches.

In Chapter 3, we look at the pricing dynamics of the ESM/EFSF bond transactions concerning investor demand and investigate in particular whether there are indications that the NIP is economically used as primary market pick-up for investors, i.e., that the NIP tends to be lower for larger order books and vice versa. The results are highly relevant to assess and fine tune the pricing in syndicated transactions.

In Chapter 4, we discuss the drivers leading to exceptionally large order books in ESM and EFSF transactions. Specifically, we investigate whether the number of orders is a main explanatory factor for investor demand. We further analyse whether there are indications that investors increase their orders in expectation of large order books, leading to a phenomenon often called "order book inflation". This analysis helps clarify to what extent investor orders reflect real demand and therewith are a useful measure for the buy side activity of the primary market.

\subsection{Data}

Our analysis is based on a data warehouse holding all order books of syndicated transactions of the ESM and EFSF. Each order book consists of the order volumes that investors placed in a particular transaction. Hence these volumes are the natural measure of investor demand, and Chapter 4 gives indications that there is no significant bias between placed orders and real demand.

A particular strength of the data set is that investors that appear in different order books are matched, meaning that all orders of the same investor are assigned to this investor. This way it is possible to trace individual investor behaviour over a period of several years. This feature is necessary in order to analyse the appearance of order book inflation as carried out in Chapter 4. It should be noted that the order books are created by the bookrunner of the respective transaction, which is one of the members of the syndicate. Hence, the order books are stemming from different sources, and creating a joint data set with matched investors is demanding and has not been done before in the literature.

Also, the investors are carefully categorised into six different types, which allows for the analysis of behaviour specific to each type. Numerous characteristics such as the tenor, issuance volume or tranche are included to serve as possible explanatory variables in the analysis. We group the investors into six categories: Central Banks and other Public Institutions (Supranationals, Agencies, Sovereign Wealth Funds, Municipalities), Banks (including Bank Treasury), Bank Trading, Asset Managers, Brokers / Hedge Funds and Pension Funds / Insurance Companies.

For the purpose of this paper, we excluded all order books before 2014. The reason is the irregular demand structure in the early phase of the ESM and EFSF compared to the period since 2014 as seen in Figure 1. It shows the yield advantage of ESM and EFSF bonds in the secondary market in relation to comparable German bonds (so called "benchmark bonds" ${ }^{3}$ in the euro area).

\footnotetext{
${ }^{3}$ To be distinguished from the "benchmark issuances" as explained in Chapter 0.
} 
Technically, it is the yield difference (yield spread) of the German bond and the ESM/EFSF bond at issuance minus the new issue premium. From the first issues until the end of 2013, this difference substantially declined, reflecting the successful establishment phase of the ESM as an issuer. Overall, the data set for this analysis, from January 2014 until September 2020, contains 97 syndicated issuances with 11,935 individual orders, a total issuance volume of $€ 259$ billion and a total order volume of $€ 545$ billion.

Figure 1 : Benchmark Spread in basis points of the bond yield at issuance with NIP subtracted for EFSF and ESM bonds

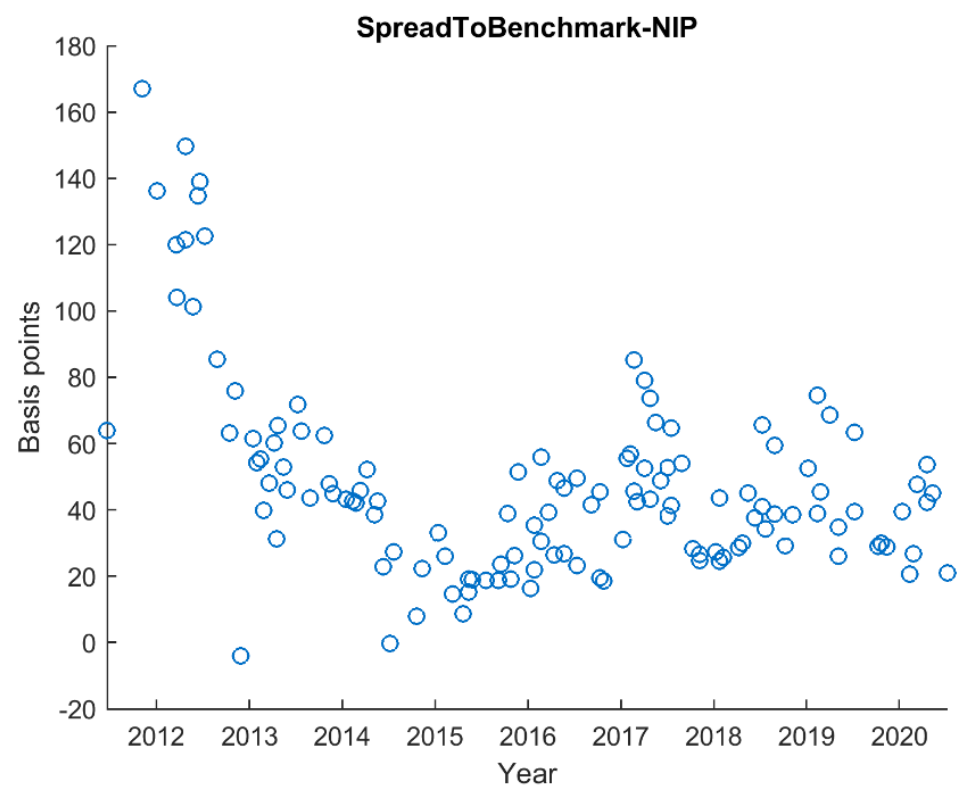

EFSF \& ESM bonds primary market

\section{Main market segmenting: Benchmarks and Taps, Maturity buckets}

In this chapter we take a closer look at the characteristics of the notional, the tenor and the issuance tranche (benchmark/tap) as fundamental determinants of investor demand.

\subsection{Benchmark versus Tap}

Figure 2 : Comparison of average demand, notional and oversubscription for benchmark and tap issuances of EFSF and ESM bonds
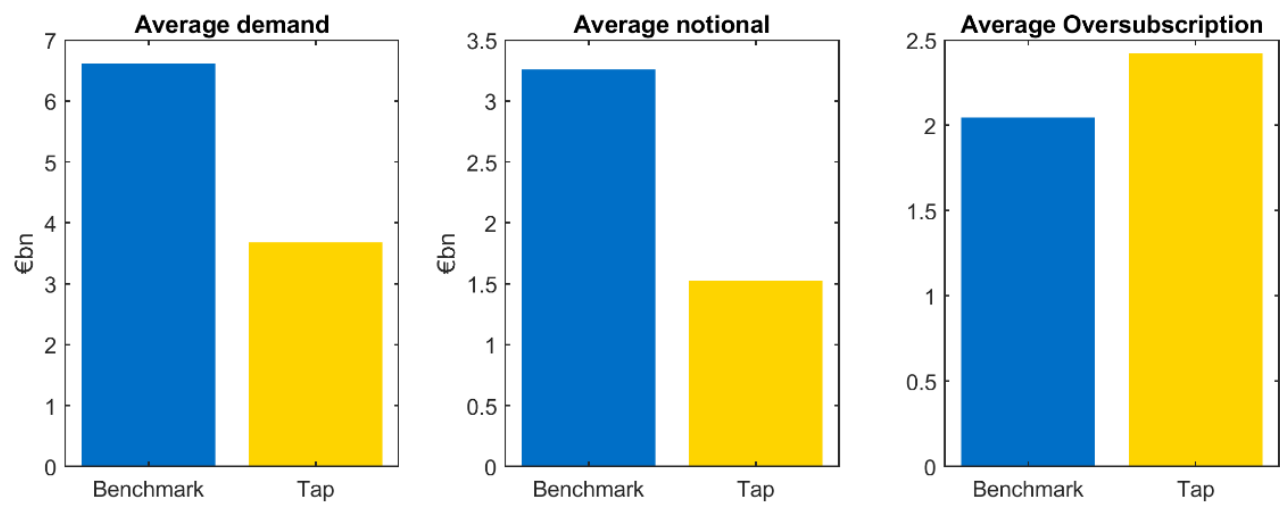

EFSF \& ESM bonds primary market. 
We observe the following characteristics when comparing benchmark issuances and taps: first, the average investor demand in benchmark transactions is approximately twice as large as the demand in tap issuances (Figure 2). This relation is highly significant, and we can reject the null hypothesis that demand in taps is larger than in benchmark issuances.

The fact that investor demand is substantially lower for taps is already taken into account when deciding the notional of the transaction. That said, the average notional of taps relative to the demand is smaller than in benchmark issuances, resulting in a larger average oversubscription of taps, as can be seen in Figure 2.

\subsection{Tenor buckets}

Looking at average investor demand in different tenors, there is a general pattern that long maturities have lower demand. However, a more detailed analysis suggests that the relation is slightly more complex, as shown in the subsequent figures. For a statistical assessment, we group the issuances in four tenor buckets: short maturities $(<3 \mathrm{Yr})$, the 5-year bucket $(3 \mathrm{Yr}-7 \mathrm{yr})$, the 10 year bucket ( $7 \mathrm{Yr}-12 \mathrm{Yr}$ ) and long maturities (>12Yr).

Figure 3 : Comparison of average demand, notional and oversubscription for all issuances of EFSF and ESM bonds
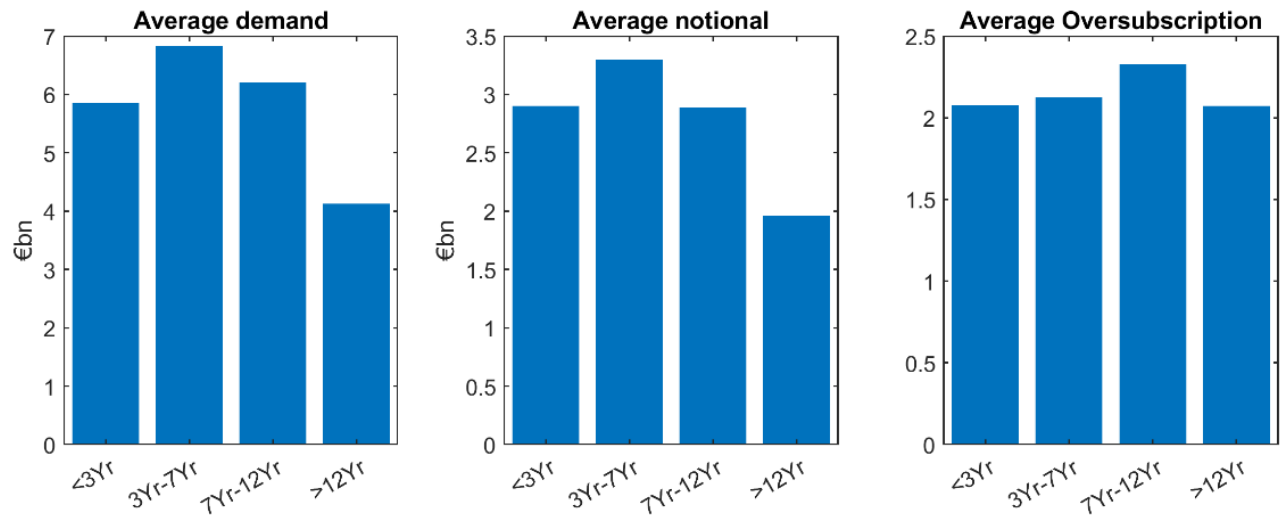

EFSF \& ESM bonds primary market

Our main finding is that demand for shorter maturities is larger than for long tenors, with the exception of the shortest maturities $(<3 \mathrm{Yr}$ ) which include only a small number of issuances (left hand side panel of Figure 3). The same "lower demand for longer tenors" pattern can be seen for the average notional (mid panel of Figure 3). As oversubscription is defined as the ratio of demand divided by notional (issue size), the trends for demand and notional roughly cancel out, leading to almost the same average oversubscription (right hand side panel) for the different tenor buckets. Grouping issuances in short tenors ( $<7 \mathrm{Yr}$ ) and long tenors ( $>=7 \mathrm{Yr}$ ), a two-sample t-test supports the hypothesis of larger demand for shorter tenors at a 5\% significance level (see Appendix).

Looking at benchmarks and taps separately, we confirm our main finding, which is larger demand for shorter tenors, particularly holds for benchmarks and is significant at a $5 \%$ level in a two-sample setup as described above. In contrast to this, tap issuances show (non-significant) higher demand for longer tenors (Figure 4 and Figure 5). Moreover, for benchmarks, demand for longer tenors is well reflected through smaller notional for larger demand. Also, as we can see in Figure 4, it leads to an overall constant and only slightly decreasing oversubscription for increasing tenors. 
In contrast, for taps, demand for longer tenors is increasing (except for the longest tenor bucket), resulting in higher oversubscriptions for tapped issuances of longer tenors, as can be seen in Figure 5.

Overall, across benchmark and tap issuances, we see an almost balanced oversubscription for longer tenors. This indicates that on average, the varying investor demand in the different maturity buckets is very well reflected in the notional. In other words, market demand for different tenor buckets was overall well matched by the corresponding ESM/EFSF supply (Figure 3).

Figure 4 : Comparison of average demand, notional and oversubscription for benchmark issuances of EFSF and ESM bonds
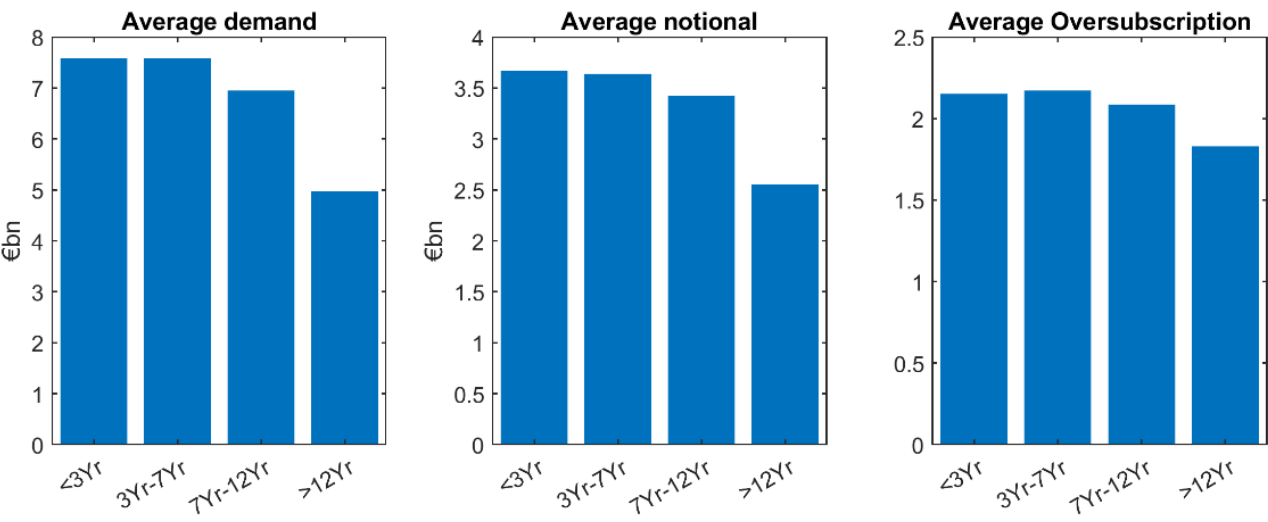

EFSF \& ESM bonds primary market

Figure 5 : Comparison of average demand, notional and oversubscription for tap issuances of EFSF and ESM bonds
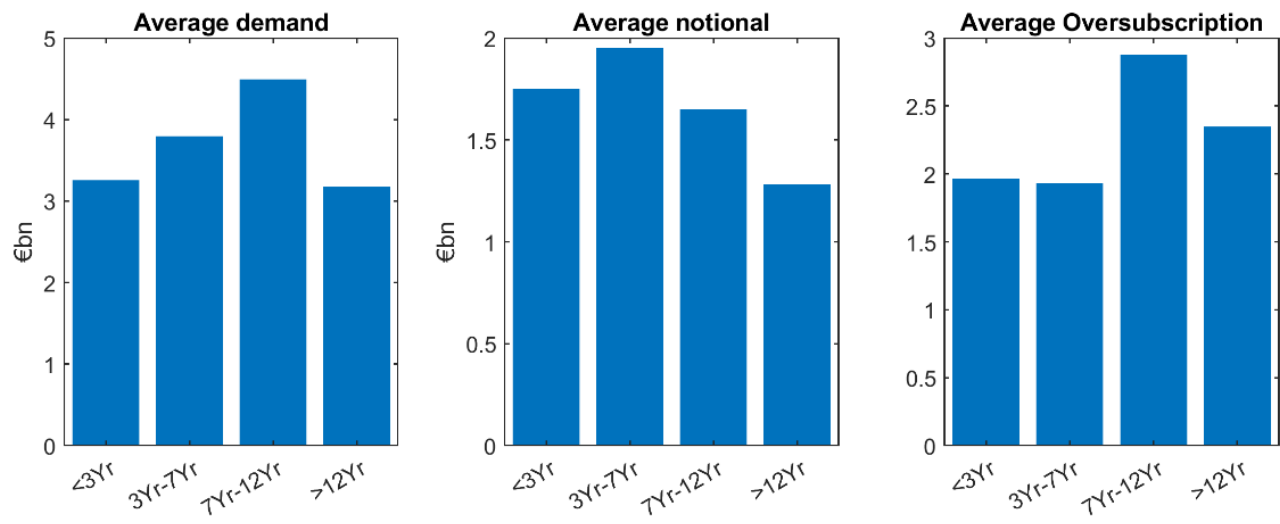

EFSF \& ESM bonds primary market

\section{Tuning the price: The New Issue Premium}

The objective of a bond issuance transaction is not only to cover the liquidity needs according to the funding plan in an asset liability management (ALM) sense, but also to support the long-term funding strategy. This long-term strategy includes developing a diversified and reliable primary market investor base and a liquid secondary market. Although the ESM does not actively trade in the secondary market, it is a stakeholder, as stable pricing, low volatility and high liquidity contribute to the confidence of primary market investors and lowers the risk premium of ESM issuances relative to the Bund benchmarks. To fulfil these secondary objectives, a certain 
oversubscription of the order book is a necessary condition for the funding and investor relation team to allocate orders to achieve a diversification in terms of investor countries and investor types. As the goal of ESM is to ensure primary market access even in severe stress situations such as during the European sovereign debt crisis, a diversified international investor base also outside of Europe is a substantial strategic asset. A moderately oversubscribed order book also signals solid market access and is hence desired by the institution.

At a fixed funding size, maturity schedule and issuance calendar, the new issue premium (NIP) is an adjustment tool set by the funding team to enable their desired allocation. Naturally, investors can be expected to increase their demand with an increased NIP offered by the issuer. Hence, if the new issue premium is set too low, it might not be possible to implement the desired allocation structure due to a lack of demand and the issued bond might underperform on the first day of trading. However, an excessively high new issue premium is also undesirable. The obvious reason is that it would be an overspending of taxpayers' funds to investors. It might also motivate additional investors to submit inflated orders and then to immediately sell the new issue on the first trading day and thereby realise the NIP, hence sending an economically wrong signal of risk and underpricing to the market.

If the NIP is set correctly, it supports a modestly positive performance of the new issue on the first trading day, thus sending a stabilising signal to the market. Large sell volumes on the first day on the secondary market or an overly inflated order book could be signs of a too generous NIP. As the funding officers set the NIP at the beginning of the book building and possibly adjust it during the that process, the NIP incorporates not only their expectation, but also their reaction to the received investor demand.

To summarise these considerations, the investors are expected to have ceteris paribus larger demand for issuances with a higher NIP, which would, ceteris paribus, result in a positive correlation between NIP and investor demand. On the other hand, as the NIP is an active tool of the funding officers to react to low demand, the NIP could also be smaller for large order books and higher for smaller order books. In other words, NIP and order volume could be negatively correlated.

Our hypothesis is that the latter effect is the dominating one, leading overall to a negative correlation. As both the NIP set by the issuer and total investor demand already include reciprocal expectations, we put the hypothesis as a correlation, and not as a linear relationship between an explained and an explaining variable. Then we discuss the significance of the reported correlation using a bootstrap analysis. 
Figure 6 : Distribution of correlation of NIP and total demand as calculated by bootstrapping method

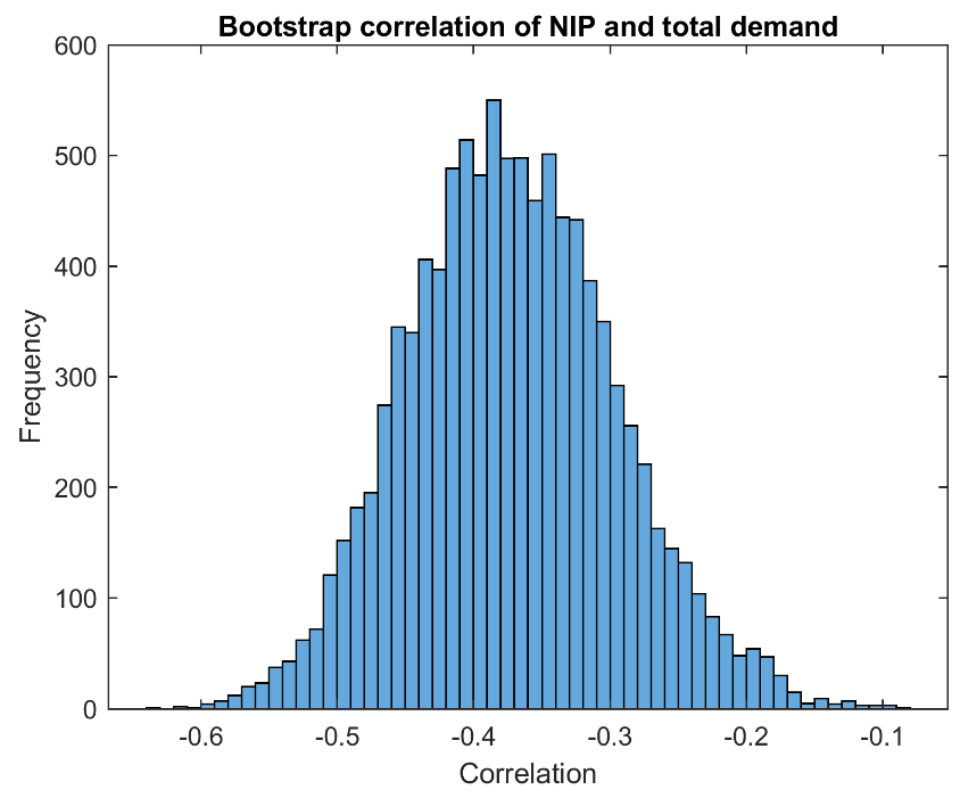

EFSF \& ESM bonds primary market

It should be noted that this analysis focuses on first issuances (benchmarks) only. The reason is that for taps, a secondary market already exists for such bonds, and the danger of cannibalising the secondary market limits the magnitude of the NIP.

Indeed, we observe a negative correlation of -0.3734 between total demand and NIP in the dataset of all orders between 2014 and September 2020. To assess the statistical validity of the reported correlations, we compute the standard deviation of 10,000 bootstrapped correlations. As an example, Figure 6 shows the histogram of 10,000 bootstrapped correlations between the total demand and the new issue premium (NIP). The mean of the bootstrap samples is $\mu=-0.3735$. It shows a slight deviation to the empirical correlation due to the random sampling. The standard deviation of the bootstrap samples is $\sigma=0.0761$. We are using the standard deviation to visualise the statistical noise in the correlation estimator in the form of an error bar in the correlation bar plots. The full width at half height (FWHH, also called "half-width") of a Gaussian distribution with a standard deviation of $\sigma$ would be roughly $2.355 \times \sigma$. So with $\sigma=0.0761$, we would have a FWHH of 0.18 . Roughly, this resulting FWHH number is consistent with the width of our example bootstrap histogram at its half height. Our interpretation of this bootstrap histogram is that the distance of the point estimate to zero is significantly larger than the statistical noise in the correlation estimator, visualised by the width of the histogram around the mean value: The peak has a distance of $\mu / \sigma=4.9$ or $\mu / \mathrm{FWHH}=2$ from zero.

We conclude that this analysis strongly supports our hypothesis that NIP and investor demand are negatively correlated. This confirms the assumption of an economical strategy for NIP pricing.

It becomes apparent that the dataset hardly contains any order books with very low demand and very small NIP, which is not surprising, as the funding team would have increased the NIP to improve demand already before the final NIP was set. In the opposite scenario of unexpectedly strong demand, the funding officers might have even increased the issue size in addition to decreasing the NIP. Hence, it is not surprising that the dataset does not include order books with very high demand and very high NIP either. 
In Figure 7 and 8, we take a more granular look at the correlation between NIP and investor demand, and at the same time we translate the bootstrap results to a correlation bar graph with additional error bars, the width of the error bars reflecting the standard deviations. In order for the point estimate to be statistically significant beyond the noise, the error bar around the point estimate should show a substantial distance to the zero level.

Figure 7 shows the correlations between NIP and the total order book demand sorted into maturity buckets. Across all maturity buckets, the correlation estimate (i.e. the y axis value of the filled blue bars) is negative, but the standard deviation of the bootstrap (i.e. the length of the vertical error bar) is substantial. For maturities below three years, the correlations are not significant, as the error bar also includes the zero-correlation value on the $y$ axis. This can be explained by the smaller number of issuances in this bucket.

Figure 7 : Correlation of NIP and demand per maturity bucket

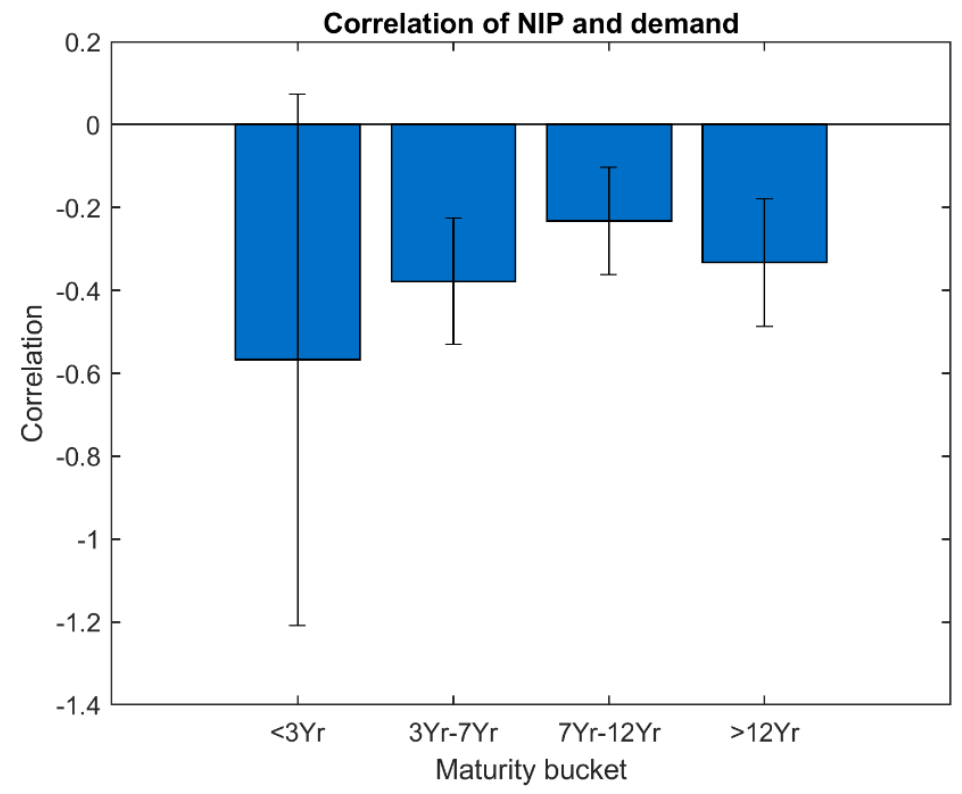

EFSF \& ESM bonds primary market

A similar bar chart with investor-type buckets instead of maturity buckets (Figure 8 ) shows negative correlations for all investor types except for insurance companies and pension funds. The highest significance of the correlations can be observed for the two investor types "Banks" and "Brokers/Hedge Funds", as they show the most negative correlations and the smallest relative standard deviations. Due to their shorter holding periods and more tactical behaviour, those two investor types are not considered as strategic investors. Typically, the NIP would not be used to attract more demand specifically from those two investor groups. However, the stronger and more significant negative correlations of these two investor groups suggest that in a situation of high demand from these investors, the new issue premia are lowered and therefore not used as a tool to generate additional demand. Investors' "Pension Fund/Insurance company" bucket shows significant positive correlations between order amount and NIP. 
Figure 8 : Correlation of NIP and demand for different investor types

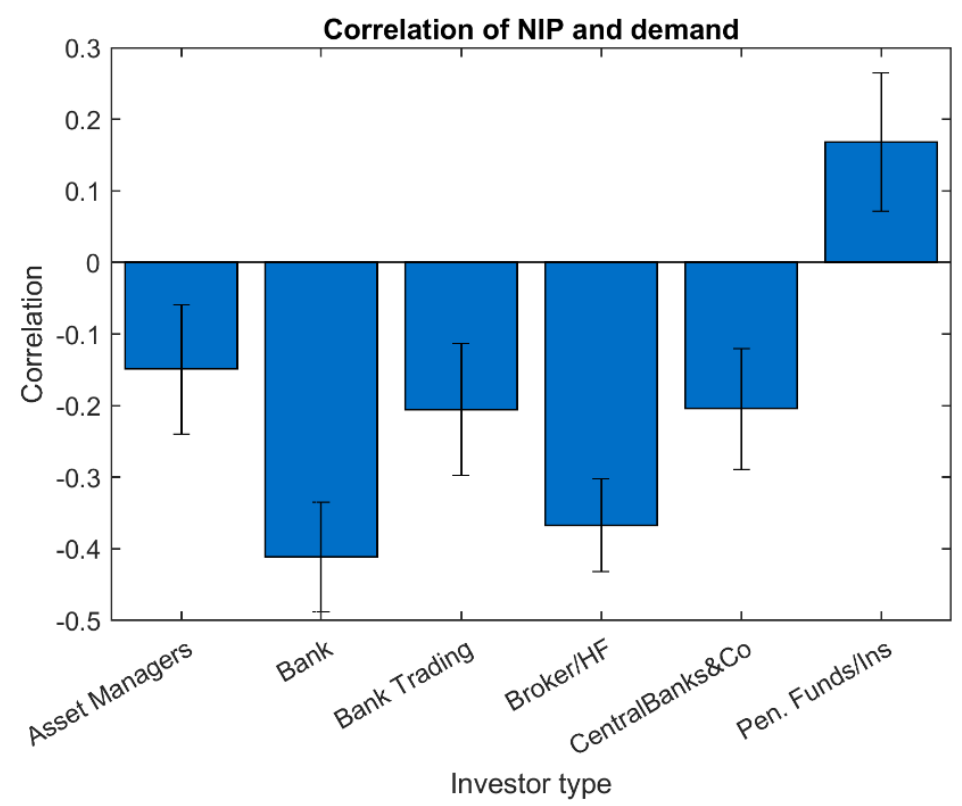

EFSF \& ESM bonds primary market

\section{Are there indications of order book Inflation?}

The following analysis investigates what the main drivers for large order books are. Clearly, large order books result from either a collection of large orders, a large number of orders, or a combination of both. While the number of orders from many different investors clearly stems from a broad interest among the investor base, larger orders could be stemming from either genuine demand or by strategic considerations: in expectation of a large order book and a small allocation share, investors might increase their orders, which again would further increase the overall order book size. Such a dynamic would lead to extremely large order books consisting of unusually large orders.

In this analysis, we look for signs that may indicate that investors tactically deviate from their real demand. Macroeconomic or market specific factors that change genuine or "real" demand of investors are not considered here. Hence we look for patterns that are unlikely to be triggered by economic factors, such as extremely large behavioural changes, out of proportion with macroeconomic changes, or different behaviour of investors in the same economic environment.

Let us first have a look at the distribution of total demand across all issuances in absolute terms and relative to the issuance volume (Figure 9). 


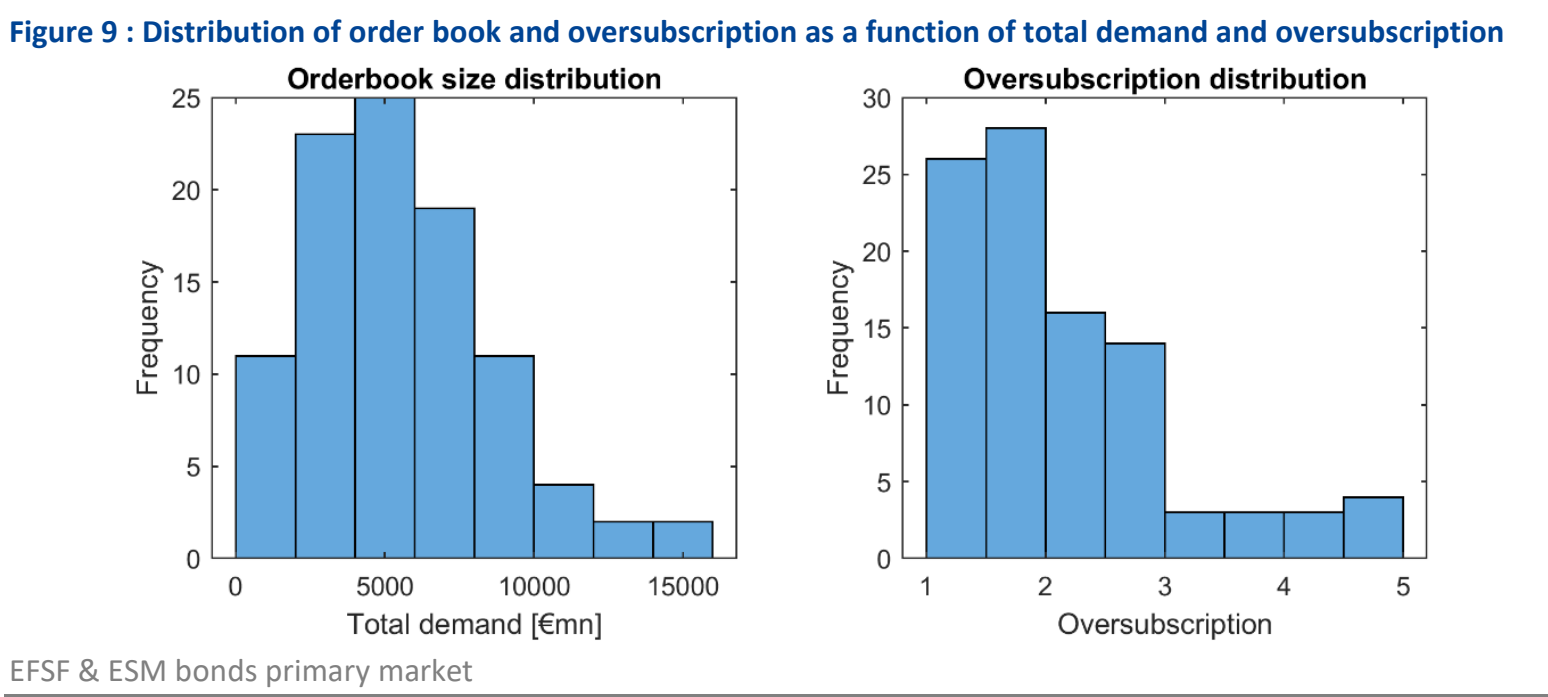

We observe a considerable variation in order book volume both in absolute and relative terms (oversubscription), yet the larger the oversubscription, the lower its frequency (Figure 9). Interesting is the "tail" with oversubscriptions larger than 4, which seems to be outside a natural distribution of order book sizes.

We now turn to the size and number of orders in relation to the order book size. Figure 10 shows that in ESM and EFSF issuances, large order books usually stem from an increased number of orders and a moderate increase in the average order size.
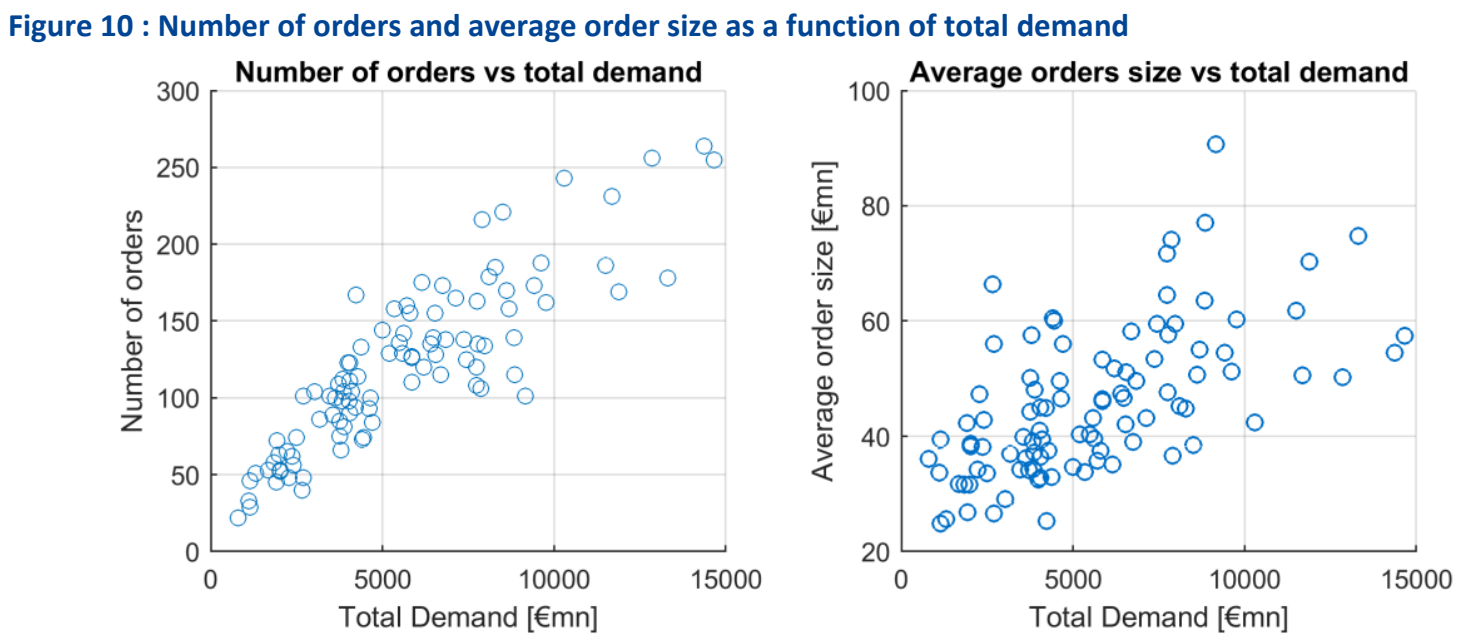

EFSF \& ESM bonds primary market

A simple linear regression (without intercept) shows a significant impact of the number of orders on the order book size (total demand) ( $p$-value $<0.01 \%$ ), and this model has an R-squared of $76.2 \%$. Hence the correlation between number of orders and total demand is $87.3 \%$. Another way to show to what degree the large order books are determined by the order number is presented in Table 1. 
Table 1: Averages of small and large order books

\begin{tabular}{|l|c|c|c|}
\hline & Avg order book $(€ b n)$ & Avg order $(€ m n)$ & Avg order number \\
\hline Books $<=€ 5 b n$ & 3.16 & 39.64 & 82 \\
\hline Books $>=€ 10 \mathrm{bn}$ & 12.57 & 57.74 & 223 \\
\hline
\end{tabular}

EFSF \& ESM bonds primary market.

Assuming the average order size from small order books of $€ 39.64$ million, the average number of orders of large order books (223) would lead to an order book size of $€ 8.8$ billion, which is $70.26 \%$ of the average order book size of large order books. In other words, more than $70 \%$ of a large order book can be explained by the larger number of orders in comparison to smaller order books.

This strongly supports our hypothesis that the number of orders is a dominant driver of the order book size.

The average order size correlates with total demand on a much weaker level, at a point estimate of 0.6109. The scatterplot of average order size versus total demand is upward sloping, but this effect is weaker than compared to the number of orders, as seen in Figure 10. 
Figure 11 : Number of orders and average order size as a function of total order book demand for different investor types
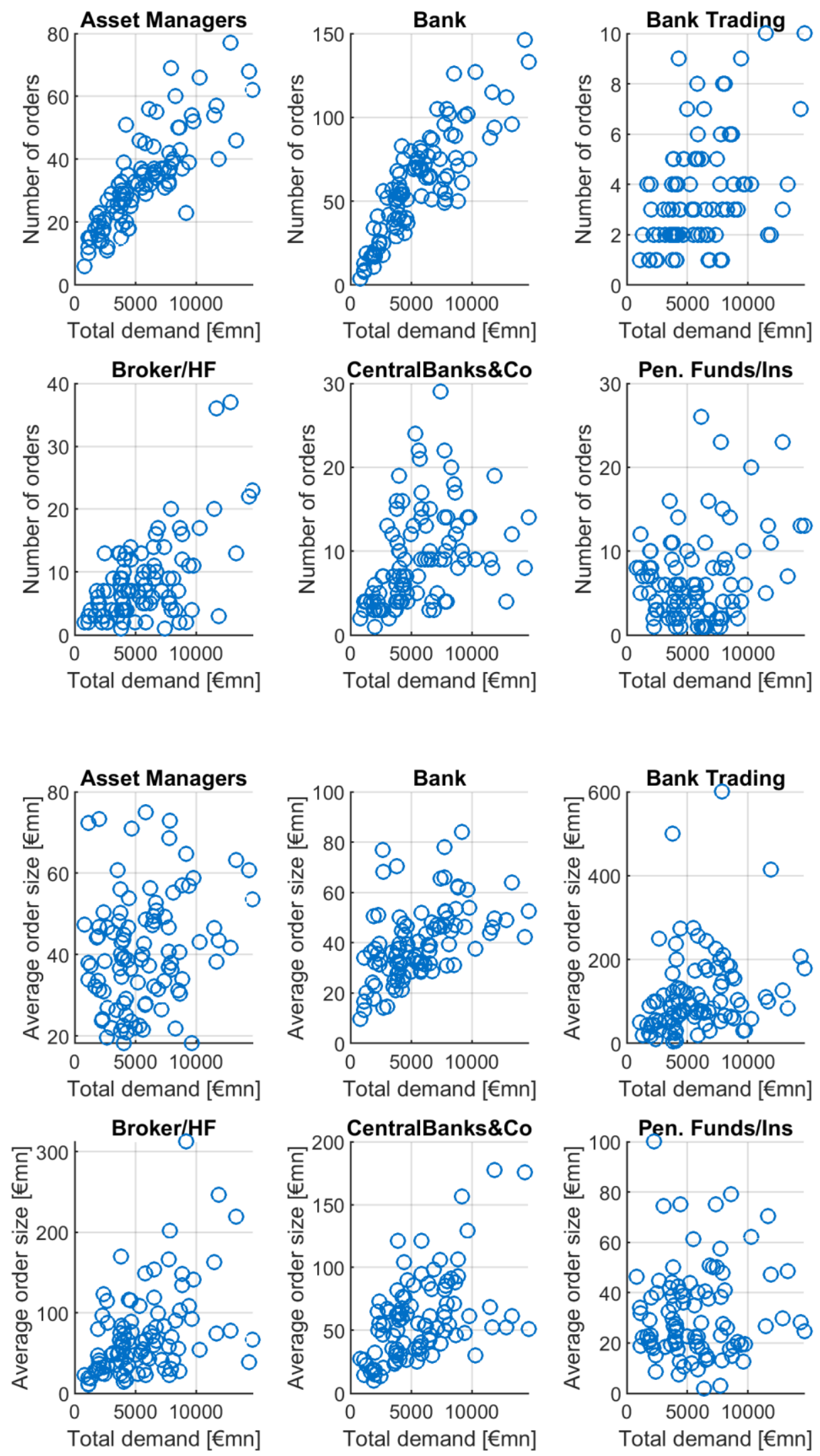
This pattern is not equally consistent among different investor types, as can be seen in Figure 11 . For higher order book sizes, we see a large number of investors from asset managers, banks, brokers and central banks, with particularly high correlations for asset managers and banks. The average order size tends to be larger the higher the total demand, mainly for banks and asset managers, and to a lesser extent for brokers/HF and central banks. Neither the number of orders nor the average order book size of pension funds shows a clear dependence pattern relative to total demand.

As previously noted, a higher average order size can be both caused by the market environment leading to increased demand from many investors, and by tactical behaviour of investors in expectation of a large order book. In the latter case, such a book can be called an "inflated order book" if it is the result of tactical (inflationary) behaviour of many investors. Since we do not know whether an investor's order tactically deviates from its real demand, we cannot directly identify inflated orders. Instead, we examine exceptionally large orders, or "oversized" orders, defined at a granular investor level. If there are multiple oversized orders in large order books, this can be an indication of an inflated order book: investors expect that other investors might increase their order in expectation of a large order book and hence increase their order.

Assuming that each investor has a certain level of regular investment, we look at large deviations from the average order volume for each specific investor. Obviously, we need to define a threshold regarding the order volume relative to a "regular" order volume. In this study we define an order of an investor as being oversized when it is larger than three times the median order of this investor. This is a heuristic approach, and other thresholds of same magnitude deliver similar results. We can characterise an inflated order book by the simultaneous occurrence of many oversized orders. Hence, such an inflated order book would be particularly large. Indeed, we see an increased share of oversized orders for larger order books, yet they also appear in smaller order book size issuances as presented in Figure 12. This said, not all oversized orders can be viewed as inflated orders.

Figure 12 : Number share of oversized orders as a function of total order book demand

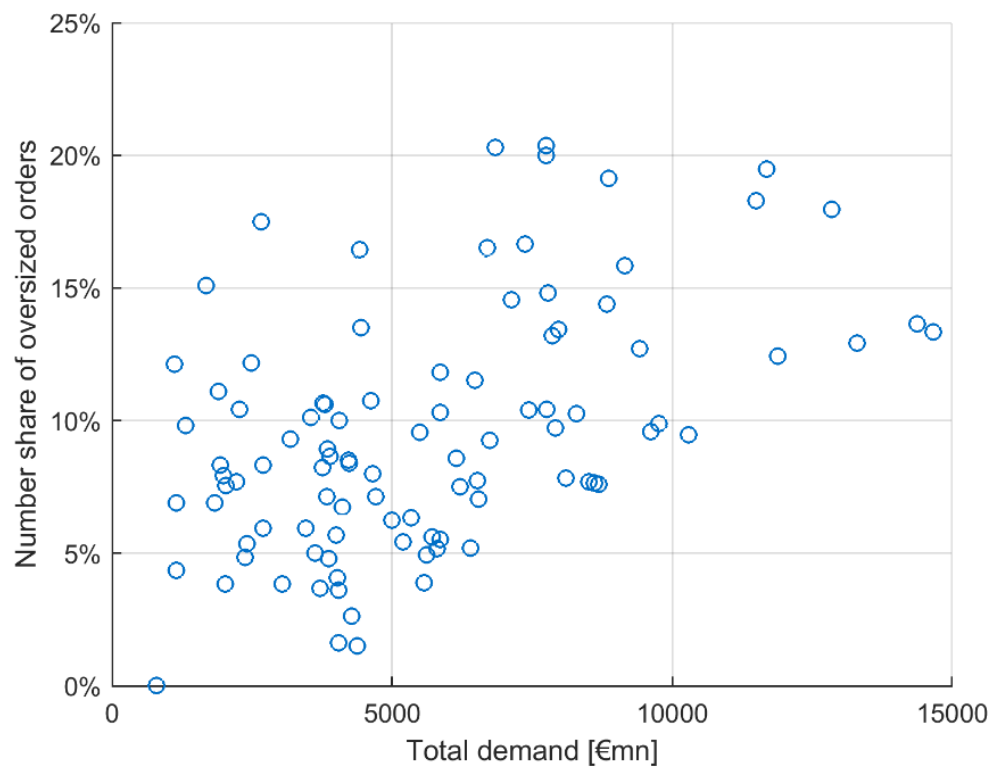

EFSF \& ESM bonds primary market

Looking at the different investor types (Figure 13), we see many oversized orders in large order books for banks, and to a lesser extent, for asset managers. Bank trading, broker/hedge funds, 
central banks and pension funds/insurance companies do not show the characteristic pattern of an increasing share of inflated orders as a function of total demand.

Figure 13 : Number share of oversized orders as a function of total order book demand for different investor types
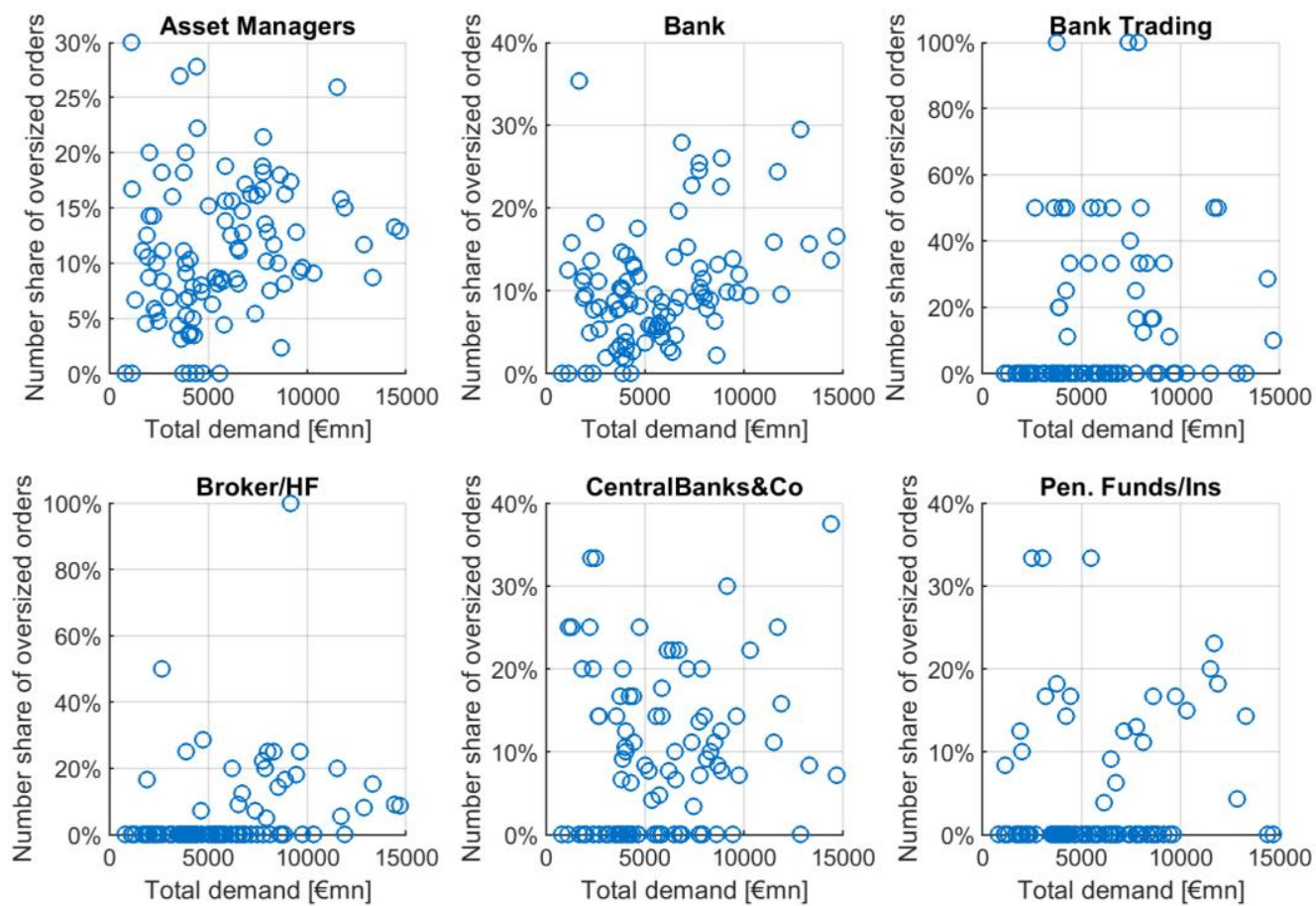

EFSF \& ESM bonds primary market

We evaluate this pattern of oversized orders in large order books by studying the share of oversized orders among the different investor types. We make use of the fact that central banks and other public entities do not inflate their orders since they can expect a high allocation share (usually more than 90\%). The reason is that they are regarded as strategically important and hence preferred investors. Thus we regard their order size distribution as unbiased by inflationary tendencies. Notably, oversized orders by central banks and other public entities constitute $9 \%$ of their total orders. For banks, oversized orders represent $10.6 \%$ of their orders, and for asset managers the figure is $11 \%$. We deduct from this data that banks and asset managers only have $1.6 \%-2 \%$ more oversized orders, which is insufficient to assume inflationary behaviour behind it. We conclude that order book inflation was not a significant feature in EFSF and ESM syndicated transactions between January 2014 and September 2020. 


\section{Conclusions}

This study focuses on stylised facts of investor demand dynamics in syndicated bond transactions, namely the main constituents segmenting investor demand, the pricing dynamics concerning investor demand, and a possible explanation for the apparently large order book size volatility.

The tranche of the issuance (benchmark or tap) and its tenor are main driving factors of investor demand. A benchmark issuance generates on average a significantly larger order book than a tap. Further, we observe that the pattern of lower demand for longer tenors is significant for benchmark issuances only, while the opposite is true for tapped issuances, yet not significantly. Overall, across benchmark and tapped issuances, the different investor demand in the different tenor buckets is well reflected by the choice of the notional, implying an almost constant oversubscription across tenor buckets. This indicates that market demand for longer tenors overall matched the corresponding ESM/EFSF supply well.

We observe that the new issue premium (NIP) has been used economically in ESM/EFSF transactions in the sense that it had a significant tendency to be higher in market circumstances that were showing less investor demand and lower in market circumstances that were showing higher investor demand. This indicates an economical issuance practice where the pricing was an accurate reflection of investor demand at different price levels.

Finally, we do not find indications of significant order book inflation in ESM/EFSF transactions in the analysed period. We base our analysis on the definition of "oversized orders" as those deviating substantially from the median order of each investor. We observe an increasing percentage of oversized orders as a function of total demand and find a larger share of oversized orders from banks and asset managers, but not as a significant feature of the aggregated order book of all investors. Instead, we show that the number of orders is the main and highly significant driver of investor demand, with an explanatory power of over $76 \%$. This indicates that orders in syndicated order books are a good measure of investor demand in the primary market. 


\section{REFERENCES}

Athanasopoulou, M., Consiglio, A., Erce, A., Gavilan, A., Moshammer, E., Zenios, S.A., 2018. Risk management for sovereign financing within a debt sustainability framework, ESM Working Paper, No.31.

Beetsma Roel et al, 2021. The maturity of sovereign debt issuance in the euro area, Journal of International Money and Finance.

Ben Dor, A. \& Xu, J. 2015. Concessions in Corporate Bond Issuance: Magnitude, Determinants, and Post Issuance Dynamics. Barclays Bank PLC, London.

Boyd Buis \& Mary Pieterse-Bloem \& Willem F.C. Verschoor \& Remco C.J. Zwinkels, 2020. Expected Issuance fees and market liquidity, Journal of Financial Markets, 48, 100514.

Ding, Yi \& Wei Xiong \& Jinfan Zhang, 2020. "Overpricing in China's Corporate Bond Market," NBER Working Papers 26815, National Bureau of Economic Research, Inc.

Goldberg, R. S., Ronn, E. I. 2013. Quantifying and Explaining the New Issue Premium in the Post Glass-Steagall Corporate Bond Market. Journal of Fixed Income, 23(1), 43-55.

Goldreich, David: Underpricing in Discriminatory and Uniform-Price Treasury Auctions. Journal of Financial and Quantitative Analysis, Jun., 2007, Vol. 42, No. 2 (Jun., 2007), pp. 443-466

Goldstein, Michael A. , Hotchkiss, Edith S. and David J. Pedersen: Secondary Market Liquidity and Primary Market Pricing of Corporate Bonds. Journal of Risk and Financial Management, 2019, 12(2), 86.

Greenwood, R., Hanson, G., Stein, J.C., 2015b, A comparative advantage approach to government debt maturity. Journal of Finance 70, 1683-1722.

Jud, Ramon 2020: Primärmarktemissionsprämie am US-Dollar Markt für Unternehmensanleihen: Die Sicht des institutionellen Investors. Unpublished MSc thesis, Zurich University of Applied Sciences.

Maitra, A., Salt, J. \& Satchell, S. 2018. New Issuance Premium in European Corporate Bonds. Lombard Odier Investment Managers, Zurich.

Matsui, Kenji (2006). Overpricing of new issues in the Japanese straight bond market. Applied Financial Economics Letters 2:5, 323-327.

Maul, D., Schiereck, D., 2018. The market timing of corporate bond reopenings, European Journal of Finance.

Moessner, Reinhild. 2018. Effects of asset purchases and financial stability measures on term premia in the euro area. Applied Economics, 50:43, 4617-4631.

Nagler, Florian and Ottonello, Giorgio, Inventory Capacity and Corporate Bond Offerings (November 9, 2020). BAFFI CAREFIN Centre Research Paper No. 2017-48, Available at SSRN: https://ssrn.com/abstract=2896758 or http://dx.doi.org/10.2139/ssrn.2896758 
Scalia et al, 1997. Bidder Profitability Under Uniform Price Auctions and Systematic Reopenings: The Case of Italian Treasury Bonds, Bank of Italy Working Paper no. 303. 


\section{ANNEX}

Significance tests for investor demand in different subgroups:

1. Benchmark/Tap

H_O: demand in taps is larger than in benchmark issuances.

Result: (number of benchmarks, number of taps, p-value)

\begin{tabular}{|l|r|r|c|c|c|}
\hline & $\begin{array}{c}\text { Number of } \\
\text { benchmarks }\end{array}$ & $\begin{array}{c}\text { Number of } \\
\text { taps }\end{array}$ & $\begin{array}{c}\text { Mean order } \\
\text { book size } \\
\text { benchmarks }\end{array}$ & $\begin{array}{c}\text { Mean order } \\
\text { book size } \\
\text { taps }\end{array}$ & $\mathrm{p}$-value \\
\hline All transactions & 64 & 33 & 6.62 & 3.67 & $<0.01 \%$ \\
\hline$<3 \mathrm{Yr}$ & 3 & 2 & 7.59 & 3.25 & No statistics \\
\hline $3-7 \mathrm{Yr}$ & 20 & 5 & 7.58 & 3.79 & $<0.1 \%$ \\
\hline $7-12 \mathrm{Yr}$ & 23 & 10 & 6.95 & 4.50 & $2.0 \%$ \\
\hline$>12 \mathrm{Yr}$ & 18 & 16 & 4.97 & 3.18 & $4.4 \%$ \\
\hline
\end{tabular}

2. Maturities

Group Maturities: $<7 \mathrm{Yr} v \mathrm{~s}>7 \mathrm{Yr}$

$\mathrm{H}_{-} 0$ : demand larger in larger issuances than in smaller issuances.

\begin{tabular}{|l|c|c|c|c|c|}
\hline & $\begin{array}{c}\text { Number of } \\
\text { issuances } \\
<7 \mathrm{Yr}\end{array}$ & $\begin{array}{c}\text { Number of } \\
\text { issuances } \\
>7 \mathrm{Yr}\end{array}$ & $\begin{array}{c}\text { Mean order } \\
\text { book size } \\
<7 \mathrm{Yr}\end{array}$ & $\begin{array}{c}\text { Mean order } \\
\text { book size } \\
>7 \mathrm{Yr}\end{array}$ & $\mathrm{p}$-value \\
\hline All transactions & 30 & 67 & 6.66 & 5.15 & $1.3 \%$ \\
\hline Benchmarks & 23 & 41 & 7.58 & 6.08 & $3.6 \%$ \\
\hline Taps & 7 & 26 & 3.64 & 3.68 & $47.8 \%$ \\
\hline
\end{tabular}




\section{European Stability Mechanism}

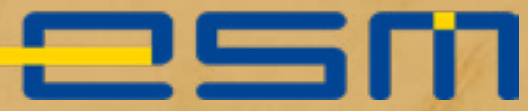

6a Circuit de la Foire Internationale 